\title{
The Effect of Psychological Capital and Knowledge Sharing on Innovation Performance for Professional Technical Employees
}

\author{
Xiaowei Qiu1, Xiaocen Yan1, Yanle Lv² \\ ${ }^{1}$ School of Government, Beijing Normal University, Beijing, China \\ ${ }^{2}$ Faculty of Education, Beijing Normal University, Beijing, China \\ Email: laizhouxiaowei@126.com
}

Received 17 July 2015; accepted 7 August 2015; published 10 August 2015

Copyright (C) 2015 by authors and Scientific Research Publishing Inc.

This work is licensed under the Creative Commons Attribution International License (CC BY). http://creativecommons.org/licenses/by/4.0/

(c) (i) Open Access

\begin{abstract}
Professional technical employees are the core staff to maintain the normal operation of the organization and the backbone of the workforce. Their levels of innovation influence and restrict the overall innovation performance levels of the corporation to a large extent. Therefore, it is of vital importance to explore and develop the innovation performance of the professional technical employees. The research, combining the theories of psychological capital, is aimed at examining the effect of psychological capital on innovation performance of the professional technical employees through the angle of knowledge sharing. Based on the hierarchical regression analysis of 347 questionnaires, the study finds that the psychological capital of the employees has a significant positive effect on the innovation performance. Meanwhile, knowledge sharing plays a completely mediating role. The corporation should lay emphasis on the psychological capital and create an atmosphere of learning organization, so as to improve and enhance the innovation performance of employees.
\end{abstract}

\section{Keywords}

Professional Technical Employee, Psychological Capital, Knowledge Sharing, Innovation Performance

\section{Introduction}

International competition is becoming increasingly fierce along with economic globalization and the develop-

How to cite this paper: Qiu, X.W., Yan, X.C. and Lv, Y.L. (2015) The Effect of Psychological Capital and Knowledge Sharing on Innovation Performance for Professional Technical Employees. Journal of Service Science and Management, 8, 545-551. http://dx.doi.org/10.4236/jssm.2015.84055 
ment of digital information technology, and innovation remains an important source of the competitive advantage. Only if corporations set up innovation consciousness and strengthen their innovation ability can they keep a foothold in the fierce competitions and remain invincible.

The overall innovation performance of the corporation depends on the team's innovation performance, while the innovation performance of the team depends on that of the individual employees. Professional technical employees' work has relatively distinctive features. They are the staffs who are engaged in scientific research and professional and technical work and create values for the corporation via using technologies and knowledge. In the practical work, professional technical employees have to be skilled in dealing with complex situations and develop new technologies and products in order to promote the technological progress and product innovation. However, most professional technical employees work with low wages, excessive workloads and heavy mental burdens, which greatly restrict their innovation performance. Therefore, with professional technical employees' innovation performance serving as the key and source of the corporation's innovation performance, only by improving the innovation level of professional technical employees will the overall performance be improved. Many current studies have shown that improving the employees' innovation performance level is the only way to gain competitive advantages [1] [2]. Exploring the factors which can enhance the professional technical employees' innovation performance level will hence play a vital role not only in improving the individual performance level but also enhancing overall innovation level of the corporation.

Foreign scholars have found that factors like personal traits, work complexity, challenge, and supportive leadership can contribute to enhancing the innovation performance of employees and drawing the conclusion from the researches of employees' personal traits, work complexity, leadership style etc [3]. As a result, individual innovation performance level is promoted by external forces on the one hand, and intrinsic motivation on the other. One of the significant intrinsic factors is the psychological capital of the employees. Psychological capital is a measurable, exploitable individual positive mental ability which can promote the job performance [4]. Existing studies have found that employees' psychological capital can largely promote work attitudes like job performance, organizational citizenship behavior [5], job satisfaction and organizational commitment [6]. Because the attitudes and behaviors like organizational commitment and organizational citizenship behavior positively affect the innovation performance [7] [8], thus psychological capital has an important psychological effect on innovation performance. Nonetheless, most current researches are confined to the public servants and general functional staff in corporation, and studies focused on the professional technical employees are still in shortage.

Since the 1990s, researches on the innovation performance of the corporation from the perspective of knowledge management have been a hot issue. Knowledge sharing is the core of organizational knowledge management, which refers to the employees or internal and external teams of the organization exchange knowledge and holds discussions within organization or across organizations through various channels in order to increase the utilization value and knowledge synergy by exchanging knowledge [9]. Many other scholars have pointed out that knowledge sharing can effectively improve the level of innovation and job performance within the organization. Since employees with abundant psychological capital are more optimistic and tough and have good interpersonal skills, they are more willing to share knowledge. As a consequence, this research argues that knowledge sharing plays an important role mediating the mechanism between psychological capital and innovation performance. This research, combining the theories of psychological capital, is aimed at examining the effect of psychological capital on innovation performance of the professional technical employees through the angle of knowledge sharing, in order to provide related recommendations for improving the innovation performance level and improve competitive advantages.

\section{Literature and Hypothesis}

With the emergence and rise of positive psychology, more and more scholars begin to focus on the psychological needs of employees. One of the important issues is focusing on the psychological capital. Psychological capital is a measurable, exploitable individual positive mental ability which can promote the job performance [4]. Psychological capital is a significant capital following human capital and social capital which affects employees' attitudes and work behaviors, and has become an important resource owned by individuals. Psychological capital includes self-confidence, optimism, tenacity, hope and other dimensions. Ke et al. based on the special background of Chinese employees and developed local psychological capital scale specifically for the Chinese employees, which launched a large-scale national study of mental capital [10]. Innovation performance refers to the 
new ideas employees intentionally generate, promote and propel in work, groups or organizations in order to help their work, groups or organizations. Innovation performance consists of the generation the promotion and the realization of ideas [11]. Studies have shown that, employees with psychological qualities like optimism and self-confidence are more likely to generate new opinions, propose new ideas, and put new ideas into practice. Employees with psychological qualities like tolerance, courtesy and modesty are easier to obtain recognition and support from others, so they are less obstructed by other employees in the organization when presenting new ideas or promoting and implementing their ideas. Barron \& Harrington proposed that confidant employees would have better innovation performance [12]. Sweetman et al. examined the effects of hope, confidence, optimism and toughness on the innovation and found that the elements of psychological capital and overall psychological capital both positively correlated with employees' innovation [13]. This leads to the following hypothesis:

H1 Psychological capital can promote the innovation performance of employees.

According to Scott \& Bruce, innovation is a multistage process, in which every stage required different activities and employee behaviors [14]. What's more, necessary information and knowledge play important roles in the three stages of generating employee's innovation performance, which includes creative production, promotion and implementation [11]. Improving organizations' innovation ability needs to set foot upon resources such as knowledge; only if knowledge sharing be realized in an organization can there be more convenience and possibility for employees to acquire knowledge. According to Jian et al., knowledge sharing, where new innovations and ideas were aroused, helped to improve innovation performance in the cooperation and exchange for process of corporation [15]. Furthermore, people can also integrate knowledge received from outside world to their own knowledge storage, arouse thinking and trigger knowledge innovation via knowledge sharing. This leads to the following hypothesis:

$H 2$ Knowledge sharing can promote the innovation performance of employees.

In this paper, we consider employees' psychological capital as a positive psychological state, which will not affect employees' performance unless it's turned into action [6]. As for innovation performance, employees' psychological capital needs to be turned into action which is beneficial to improve innovation performance to eventually have an result. What's more, innovation is a process when knowledge is transformed and generated. And it is based on knowledge sharing and knowledge integration. Moreover, only those who enjoy a higher psychological capital level can have a better mindset to keep sharing knowledge with others despite setbacks and difficulties, thus generate their own knowledge resource and key elements of innovation, as well as improve their innovation performance. According to Li, knowledge sharing affects psychological capital and innovation performance as a mediator significantly [16]. This leads to the following hypothesis:

H3 Knowledge sharing mediates the relationship between psychological capital and innovation performance.

\section{Method}

\subsection{Sample}

The article used self-report questionnaire for convenient sampling. The sample for the study was drawn from corporate professional technical employees in about 6 corporations in Beijing. Out of the total 380 questionnaires distributed, 355 copies were returned and 347 of them were valid. The effective response rate is $97.5 \%$. Invalid samples included those who didn't fill all the questions or fill the questions casually. In the 347 valid samples, males accounted for $54 \%$ and women $46 \%$; unmarried $28 \%$ and married $72 \%$. The education background ranged from high school and below to Ph.D., in which high school and below took up 5\%, specialist $15 \%$, undergraduate $57.5 \%$, master $20.8 \%$ and doctor $1.7 \%$.

\subsection{Measuring}

Psychological capital. This paper uses the scale of psychological capital developed by Ke et al. [10] and measuring by Likert six-point scale from "completely disagree" to "completely agree" ,and the overall alpha is 0.87.

Knowledge sharing. This research uses the scale complied by Bock et al. [17] and measuring based on Likert six-point scale from "completely disagree" to "completely agree" and the overall alpha was 0.87 .

Innovation performance. This paper uses the scale of psychological capital developed by Janssen [11]. This includes 9 items and is measured based on Likert six-point scale from "completely disagree" to "completely 
agree” and the overall alpha was 0.86 .

Control variables. Control variables includes gender, marriage, educational background and work experience. Specifically, gender: $0=$ female, $1=$ male; marriage: $0=$ yes $1=$ no; educational background: $1=$ "secondary vocational school and under", 2 = "bachelor", 3 = "master", 4 = "doctor"; working experience: $1=$ " 0 - 1 year", $2=$ " 2 - 4 years", $3=$ " $5-7$ years", $4=$ " $8-10$ years", $5=$ ">10 years".

\subsection{Common Method Biases Test}

In order to reduce common variance, the guidance language in the questionnaires instructed that the survey was anonymous and there were wrong answers. Also the research uses the Harman single factor test to verify the extent of homologous error of each research variable. The results suggested that all the factors together explained $33 \%$ of the total variance, and Factor 1 explained $15.53 \%$. There was no single factor explaining most of the variance, indicating common method biases are not serious.

\section{Results}

\subsection{Descriptive Statistics and Correlation Analysis of Variables}

Table 1 shows the mean value, standard deviation and Pearson correlation coefficient. The mean and standard deviation don't have any abnormal phenomena. The results show that psychological capital plays a significant role in promoting knowledge sharing $(r=0.425, P<0.001)$ and innovation performance $(r=0.335, P<0.001)$. Meanwhile knowledge sharing has a significant positive effect on innovation performance $(r=0.761, P<0.001)$. These results support $\mathrm{H} 1$ and $\mathrm{H} 2$.

\subsection{The Regression Analysis of Effect of Psychological Capital on Innovation Performance}

The research applied the regression analysis to measure the effect of psychological capital on innovation performance. Table 2 shows the effect of psychological capital on innovation performance and the relationship between psychological capital and innovation performance. The VIF of Model 1 - 3 is far less than the critical value of 10 , which shows that the model does not have the serious problem of collinearity and the results are acceptable. Model 2 shows that the $\beta$ of psychological capital is $0.391(P<0.001)$. Model 3 shows that after introducing the variables of psychological capital and knowledge sharing, the $\beta$ of psychological capital is 0.0 .056 which is lower than before and the $\beta$ of knowledge sharing is $0.752(P<0.001)$. Since considering knowledge sharing the effect of psychological capital on the innovation performance weakens, knowledge sharing completely mediates the relationship between psychological capital and innovation performance. These results support H3.

\subsection{The Path Analysis of Psychological Capital on Innovation Performance}

In order to test and verify the effect of psychological capital on innovation performance, the study uses the SEM technique and AMOS 17.0 to validate the result of regression analysis further. Based on the advice of Little et al., The index was packed. Specifically, in accordance with the factor balance method, the items of psychological

Table 1. Descriptive statistics and correlation analysis of variables.

\begin{tabular}{|c|c|c|c|c|c|c|c|c|}
\hline & Mean & SD & 1 & 2 & 3 & 4 & 5 & 6 \\
\hline 1. Gender & 0.46 & 0.499 & & & & & & \\
\hline 2. Marriage & 0.72 & 0.451 & $-0.264^{* *}$ & & & & & \\
\hline 3. Educational background & 1.74 & 0.602 & 0.002 & $0.147^{* *}$ & & & & \\
\hline 4. Work experience & 3.64 & 0.581 & $-0.271^{* *}$ & $0.557^{* *}$ & -0.008 & & & \\
\hline 5. Psychological capital & 4.17 & 0.962 & $0.133^{*}$ & 0.096 & 0.104 & -0.007 & 0. & \\
\hline 6. Knowledge sharing & 4.19 & 0.846 & 0.084 & -0.043 & -0.015 & -0.009 & $0.425^{* * *}$ & \\
\hline 7. Innovation performance & 4.04 & 0.769 & 0.028 & -0.002 & 0.049 & 0.015 & $0.335^{* * *}$ & $0.761^{* * *}$ \\
\hline
\end{tabular}

Notes: ${ }^{* * *} P=0.001 ;{ }^{* *} P=0.01 ;{ }^{*} P=0.05$. 
Table 2. Regression analysis of psychological capital and knowledge sharing on innovation performance.

\begin{tabular}{|c|c|c|c|}
\hline & \multicolumn{3}{|c|}{ Innovation performance } \\
\hline & Model 1 & Model 2 & Model 3 \\
\hline Constant & 4.053 & 3.047 & 0.960 \\
\hline \multicolumn{4}{|l|}{ Control variable } \\
\hline Gender & 0.016 & -0.054 & -0.042 \\
\hline Marriage & -0.063 & -0.118 & -0.026 \\
\hline Educational background & 0.040 & 0.029 & 0.056 \\
\hline Work experience & 0.062 & 0.063 & 0.001 \\
\hline \multicolumn{4}{|l|}{ Independent variable } \\
\hline Psychological capital & & $0.391^{* * *}$ & 0.056 \\
\hline Knowledge sharing & & & $0.752^{* * *}$ \\
\hline $\mathrm{R}^{2}$ & 0.005 & 0.151 & 0.604 \\
\hline Adjusted $\mathrm{R}^{2}$ & -0.009 & 0.136 & 0.596 \\
\hline $\mathrm{F}$ & 0.333 & 10.165 & 72.251 \\
\hline$\Delta \mathrm{R}^{2}$ & 0.005 & 0.147 & 0.453 \\
\hline F & 0.333 & 49.27 & 324.91 \\
\hline
\end{tabular}

Notes: ${ }^{* * *} P=0.001 ;{ }^{* *} P=0.01 ;{ }^{*} P=0.05$.

capital, knowledge sharing and innovation performance are packed as 3 indexes respectively. The fit index of the model can be shown in Table 3. The discriminant criteria of each index are as follows: $X^{2} / d f<3$; CFI, TLI, IFI > 0.8; RMSEA $<0.08$. From the data from Table 3, we can come a conclusion that the model fits better.

The research results can be shown in Figure 1. The results show that in the case of knowledge sharing, psychological capital of professional and technical personnel has a significant positive effect on knowledge sharing ( $\beta=0.45, P<0.001$ ); meanwhile knowledge sharing has a significant positive effect on innovation performance $(\beta=0.80, P<0.001)$. But the direct path coefficient of psychological capital on innovation performance is not significant. So knowledge sharing mediates the relationship between psychological capital and innovation performance.

\section{Discussion}

Through empirical research, this study assessed how professionals’ psychological capital and knowledge sharing affected their innovation performance. And the research hypotheses are all be verified. The result showed a significant positive correlation of psychological capital and innovation performance with its 0.391 correlation coefficient and up to 0.001 significance level. It means that this result is broadly consistent with those concerning empirical validation of psychological capital and innovation performance in existing literature. And a significant positive correlation of psychological capital and knowledge sharing has been demonstrated, too. Moreover, employees with psychological traits such as optimism and confidence are more willing to share their work results with others [18]; also, they are more willing to share their knowledge, skills and experience with others [19]. Therefore, in order to enhance innovation performance through knowledge integration, employees with more positive psychological capital have more courage to try sharing and integrating different kinds of knowledge, at the same time they are persistent to try to look for other people’s help.

\section{Management Implications}

First of all, a corporation should recruit professional technical employees with positive psychological capital in practical management and advocate tolerance, respect, modesty, contribution and other organizational cultures in 
Table 3. Fit index of the model.

\begin{tabular}{cccccccc}
\hline $\mathrm{X}^{2}$ & $\mathrm{df}$ & $\mathrm{X}^{2} / \mathrm{df}$ & CFI & TLI & IFI & NFI & RMSEA \\
\hline 44.2 & 24 & 1.843 & 0.994 & 0.990 & 0.994 & 0.986 & 0.051 \\
\hline
\end{tabular}

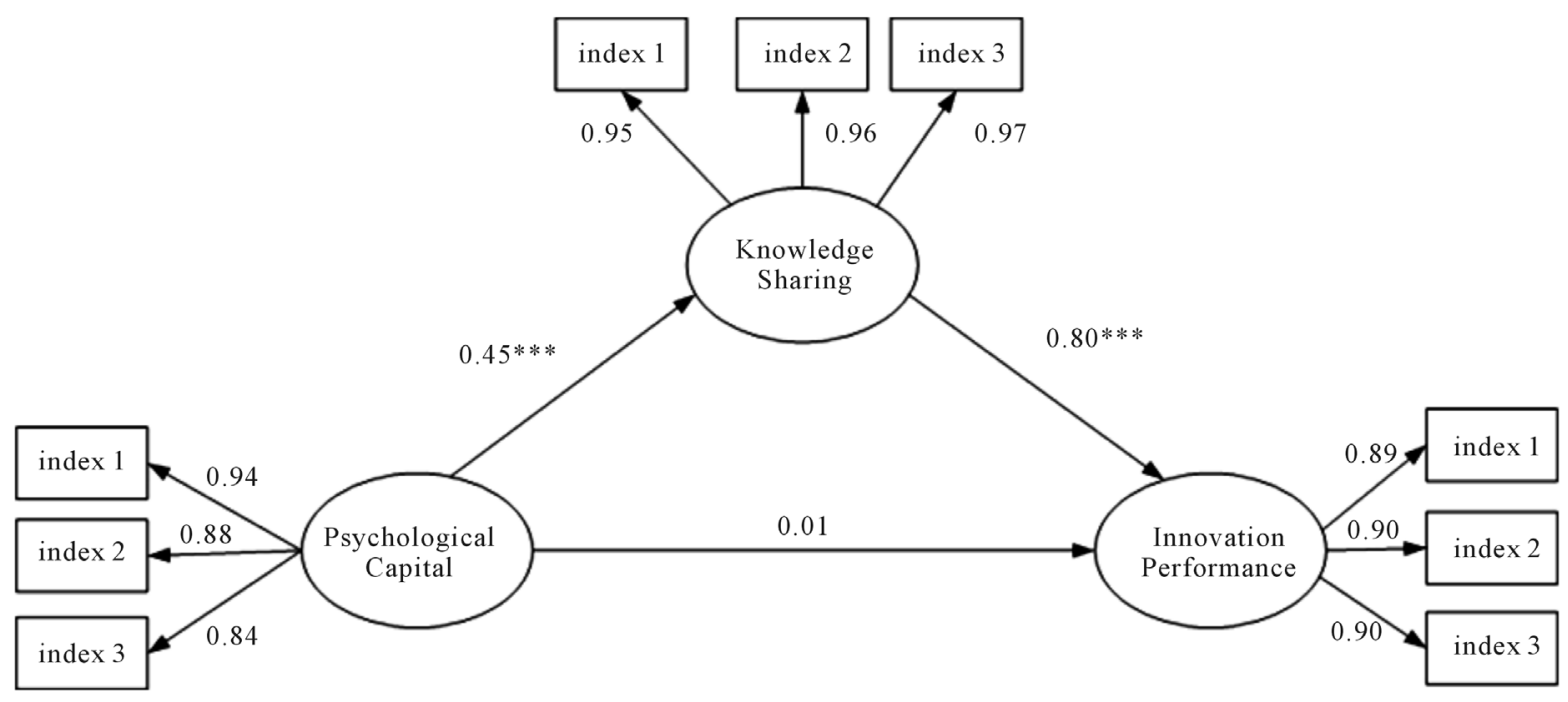

Figure 1. The SEM of the study.

daily management in order to improve psychological capital of professional technical employees and thus enhance their innovation performance.

Secondly, knowledge sharing has a significant positive effect on innovation performance. Corporation is suggested to select employees who are aware and capable of sharing knowledge. As for the current employees, corporation should foster their awareness and ability of knowledge sharing.

Finally, knowledge sharing mediates the mechanism between psychological capital and innovation. Thus, corporation should pay attention to professional technical employees’ psychological capital and their awareness and ability of knowledge sharing. The innovation performance will hence grow as long as employees are aware and capable of sharing knowledge.

\section{Limitations and Directions for Future Research}

The limitations of this study are as follows: Firstly, the distributions of samples aren't wide enough. The study mainly investigated the employees of the corporation in Beijing, which made the research more prone to regional. In the future study, the study could investigate corporation and employees from other regions to enhance the representativeness. Secondly, in this study, although the investigation was conducted in the student class and tried to reduce respondents' concerns and minimize common variance, due to the self-evaluation mode, the data obtained had some deficiencies. Yet many scholars get consistent conclusions when exploring how counterproductive work behavior affects job involvement by way of self-executive [20], the study will try to get sample data via peer assessment and self-assessment in follow-up studies in order to test fundamental hypothesis more precisely. The study will also consider collecting panel data and using longitudinal approach to ensure the reliability of the conclusions.

\section{References}

[1] Devanna, M.A. and Tichy, N. (1990) Creating the Competitive Organization of the 21st Century: The Boundaryless Corporation. Human Resource Management, 29, 445-471. http://dx.doi.org/10.1002/hrm.3930290409

[2] Kanter, R.M. (1986) Creating the Creative Environment. Management Review, 5, 11-12.

[3] Greg, R. and Oldham, A.C. (1996) Employee Creativity: Personal and Contextual Factors at Work. The Academy of Management Journal, 39, 607-634. http://dx.doi.org/10.2307/256657 
[4] Luthans, F., Avolio, B.J., Walnumbwa, F.O. and Li, W. (2005) The Psychological Capital of Chinese Workers; Exploring the Relationship with Performance. Management and Organization Review, 1, 247-269. http://dx.doi.org/10.1111/j.1740-8784.2005.00011.x

[5] Zhong, L. (2007) Effects of Psychological Capital on Employees’ Job Performance, Organizational Commitment, and Organizational Citizenship Behavior. Acta Psychologica Sinica, 39, 328-334.

[6] Ke, J. and Sun, J. (2014) The Effects of Employee’s Psychological Capital on Job Satisfaction, Organizational Commitment and Turnover Intention. Research on Economics and Management, 1, 121-128.

[7] Bao, G. and Qian, Y. (2009) Extra-Role Behavior and Team Innovation Performance: A Multiple Approach. Journal of Zhejiang University (Humanities and Social Sciences), 5, 113-121.

[8] Jafri, M.H. (2010) Organizational Commitment and Employee’s Innovative Behavior: A Study in Retail Sector. Journal of Management Research, 10, 62-68.

[9] Lin, D. and Li, D. (2005) Knowledge Management. Publishing House of Electronics Industry, Beijing, 100-101.

[10] Ke, J., Sun, J. and Li, Y. (2009) Psychological Capital: Chinese Indigenous Scale’s Development and Its Validity Comparison with the Western Scale. Acta Psychologica Sinica, 9, 875-888. http://dx.doi.org/10.3724/SP.J.1041.2009.00875

[11] Janssen, O. (2000) Job Demands, Perceptions of Effort-Reward Fairness and Innovative Work Behavior. Journal of Occupational and Organizational Psychology, 73, 287-302. http://dx.doi.org/10.1348/096317900167038

[12] Barron, F. and Harrington, D.M. (1981) Creativity, Intelligence, and Personality. Annual Review of Psychology, 32, 439-476. http://dx.doi.org/10.1146/annurev.ps.32.020181.002255

[13] Sweetman, D., Luthans, F., Avey, J.B. and Luthans, B.C. (2010) Relationship between Positive Psychological Capital and Creative Performance. Canadian Journal of Administrative Science, 28, 4-13.

[14] Scott, S.G. and Bruce, R.A. (1994) Determinants of Innovative Behavior: A Path Model of Individual Innovation in the Workplace. Academy of Management Journal, 37, 580-607. http://dx.doi.org/10.2307/256701

[15] Jian, Z., Liu, R. and Zhao, L. (2010) The Impact of Network Relationship, Trust, and Knowledge Sharing on Technology Innovation Performance. Research and Development Management, 22, 64-71.

[16] Li, F. (2014) The Effect of Psychological Capital on Employees’ Innovation Behavior-Based on Intermediary Effect of Knowledge Sharing. Commercial Times, 25, 89-91

[17] Bock, G.W., Zmud, R.W., Kim, Y.G. and Lee, J.N (2005) Behavioral Intention Formation in Knowledge Sharing: Examining the Roles of Extrinsic Motivators, Social-Psychological Forces, and Organizational Climate. MIS Quarterly, Information Technologies and Knowledge Management, 29, 87-111.

[18] Lazarus, R.S. (1991) Progress on a Cognitive-Motivational-Relational Theory of Emotion. American Psychologist, 46, 819-834. http://dx.doi.org/10.1037/0003-066X.46.8.819

[19] Sun, J., Zhang, X., Zhang, Y. and Lu, Z. (2013) The Influence of Core Self Evaluation on Individual Innovative Behavior-The Mediating Effects of Knowledge Sharing. 16th IACMR Conference-China Forum, Acta Psychologica Sinica, 2.

[20] Chao, G., Cheng, P. and Zhang, S. (2012) An Empirical Study on the Effects of Corporate Social Responsibility on Job Involvement from the Perspective of Staffs. Chinese Journal of Management, 6, 831-836. 